\title{
A REVIEW ON COMPLEMENTARY NATURES OF TANGIBLE USER INTERFACES (TUIS) AND EARLY SPATIAL LEARNING
}

\author{
G.E. Baykal ${ }^{\mathrm{a}}$, I.Veryeri Alaca ${ }^{\mathrm{b}}$, A.E. Yantaç ${ }^{\mathrm{c}}$, and T. Göksun ${ }^{\mathrm{d}}$ \\ a Design, Technology and Society PhD Program, Koç University, Ístanbul, Turkey. \\ b Media and Visual Arts Department, Koç University, İstanbul, Turkey. \\ c Arçelik Research Center for Creative Industries, Koç University, Istanbul, Turkey. \\ d Department of Psychology, Koç University, Istanbul, Turkey.
}

\begin{abstract}
Spatial skills are essential for everyday tasks, and technology blends seamlessly into children's everyday environment. Since spatiality as a term is ubiquitous in experience this paper bridges literature in two fields: theories on early spatial learning in cognitive development and potential benefits of tangible user interfaces (TUIs) for supporting very young children's spatial skills. Studies suggest that the period between 2 and 4 years of age is critical for training spatial skills (e.g., mental rotation), which relate to further success in STEAM (science, technology, engineering, arts, and math) disciplines. We first present a review of the empirical findings on spatial skills, early interventions, and tools (i.e., narrative and gesture input) recommended for training preschool children's spatial skills. By situating the work within the use and benefits of manipulatives (e.g., building blocks, puzzles, shapes) combined with digital affordances in interaction design, we address the relevance of TUIs as complementary tools for spatial learning. We concentrate on the supporting properties of TUIs that enable playful learning, make storytelling more concrete, and provide embodiment effects through physicality. Through various products found in the market and literature that address the physical-digital convergence, we invite designers and researchers to consider design practices and applicable technology that build on present efforts and paradigms in this area. To contribute to this area, we conclude with a discussion of the gaps in design methods to develop technologies for children younger than 4 years old, and propose directions for future work to leverage new tools that serve very young children's spatial learning and possible inquiries for dual payoff.
\end{abstract}

Keywords: Spatial learning, tangible user interfaces, preschool children, mental rotation.

\section{Introduction}

Spatial skills are of great importance for understanding the representations of relations within and between objects (e.g., shapes, location, paths, configurations), which are essential for everyday tasks. Training spatial abilities through hands-on interactions with physical objects (e.g., block building) before 4 years of age is found critical for effective, durable, and transferable learning for children $[54,92,96]$. Therefore, understanding and developing ageappropriate tools to facilitate these skills are important. This review of literature is situated at the intersection of two disciplines: spatial learning as a domain in cognitive development, and Tangible User Interfaces (TUIs) as an interaction approach for promoting constructional learning processes of very young children. 
TUIs are systems in which physical objects and environments are augmented through embedded computation [5, 91]. There is an increasing emphasis on investigating the interactional capabilities afforded by tangible technologies with reference to the area of preschool children's learning [59, 66, 91]. Tangible interaction that blends the advantages of digital and physical worlds has a great potential for enhancing young children's active learning [59, 90], and cognitive development [5], especially because it enables embodied and inherently spatial interaction more than other types of interfaces [5]. Although learning and cognitive functioning has received much interest from TUI designers amongst other major application domains such as problem solving, tangible programming, entertainment and engagement $[5,57,59,66,83$, 109], the use of TUIs for spatial learning as a particular domain in cognitive development has been less forthcoming. There is still need for theoretically grounded guidance that explains the means of spatial learning process to inform the TUI design in this regard [5].

Spatial skills are important for a variety of everyday tasks such as tool use (mental rotation) and navigation $[35,93]$, which are important not only in the $21^{\text {st }}$ century, but throughout the whole of human history. Importantly, spatial skills are malleable and can be improved with early training activities especially between 2 and 4 years of age [54]. Hands-on experiences with physical objects such as blocks, puzzles, and shapes at early ages have significant impacts on training children's mental rotation skills (e.g., the ability to perform rotating, folding, bending, scaling, cross-sectioning the two- or three- dimensional forms or shapes) [26, 54, 95]. Longitudinal studies in developmental studies showed that mental rotation skills are directly related to school readiness and further STEAM success [52, 65, 98, 99]. Hence, early experiences with spatial manipulatives might also provide opportunities to close the gap in STEAM interest and entry into STEAM-based occupations in a child's further life [35, 93]. It is also informed that when given in the form of a narrative, the input provides effective context for teaching spatial content in block building activities $[15,26]$. Moreover, embodiment in practice such as gesturing about rotating objects improves mental rotation performance of children at the age of four [70]. Then, what type of interactive technologies can leverage the tools that young children need along their spatial learning activities with such manipulatives?

TUIs offer the physicality of interaction through graspable, embodied or distributed mechanisms to support children's learning [59, 73, 105]. Moreover, integrating narrative and gestures are defined as typical learning domains that TUIs might enhance [59]. These tangible systems were basically inspired by block building activities [76, 108]. Yet, spatial problem solving - which relates to hands-on action, manipulation, and rotation skills - is defined as one of the knowledge gaps for tangible interaction research [3, 43]. Research is needed to better understand how TUIs can facilitate very young children's early spatial learning.

There is also lack of constructive design methods generated for and with children younger than 4 years of age in Child-Tangible Interaction (CTI) research. Until recently it was suggested that young children's developmental needs could be adequately met without computation [5]. American Psychological Association revised their guidance, recommending that technology might serve for children's development under age of 2 who are born as digital natives today in the period of the 4th industrial revolution. This era is characterized by the blurring boundaries between physical, digital and biological worlds. Thus, understanding behaviors, needs, and 
abilities of children younger than 4 years of age as active users of physical and technological materials, and delivering design guidelines to develop evidence-based, age-appropriate tangible tools appear as an important responsibility for the child-computer interaction (CCI) community. Our research attempts to address this gap in design knowledge, targeting children between 2 and 4 years of age as a period that is suggested as critical for training spatial skills for effective learning [54]. The primary focus of our review lies on the following questions:

- How can potential benefits of TUIs and training methods for spatial skills supplement each other to facilitate early spatial learning of children between 2 and 4 years of age?

- How can current design methods be tailored to design for the behavioral patterns, abilities, and needs of children under 4 years old, and to what extent can their participatory contribution in design be elicited while interacting with spatial manipulatives?

Regarding each research question, we first summarize the current state of theories and findings around child development in spatial learning and technology design in TUI. We present a review of empirical papers in cognitive development to compile the reliable measures, tools, and intervention models used in understanding children's spatial learning between 2 and 4 years of age. Next, we select current paradigms in the market and design literature that combine the use of physical-digital tools to give an insight on how children at different ages and/or ability levels might benefit playing with TUIs. Last, we report the challenges and gaps in the literature for researchers and practitioners. This review aims to bridge two disciplines to further interdisciplinary practices by considering how interactive technology and developmental trajectories found in spatial learning could, and perhaps should serve each other as complementary fields to provide opportunities for children to think, play, and learn.

\section{Spatial Skills as a Learning Domain in Cognitive Development}

\subsection{What are spatial skills and why are they important?}

Spatial learning and thinking in the early years are essential for a variety of everyday tasks, such as packing a toy box, cutting equal slices of cake for a group of people, or remembering where an object is by cue learning [35, 61, 92]. Newcombe and her colleagues (2013) divided spatial cognition into two main spheres to define the subdomains of spatial skills; navigation and mental rotation [65]. The former is related to interobject (extrinsic) representation and transformation, which involve more than one object in relation to others, and refers to being able to take perspective according to different frames of reference. The latter is related to intraobject (intrinsic) representation of individual objects and ways to transform them, which is also referred as the ability of tool-making. Intrinsic skills are regarded as one of the underlying adaptive characteristics of human species. Newcombe et al. (2013) inform that, to date, only intrinsic (mental rotation) encodings and transformations, not extrinsic skills, have been assessed in relation to STEM [65]. Furthermore, a very recent longitudinal study by Lauer and Laurenco (2016) showed that mental rotation and spatial reasoning begin as young as 6 months of age [52]. They found that infants who spend more time looking at changed orientation in the displayed images (i.e., Tetris tile pieces) maintain these abilities at the age of 
4 in terms of performing better at basic math skills [52]. Building on the previous work, this review focuses on mental rotation (intrinsic) skills and proposed training methods for preschoolers as an input to inform the design studies.

Mental rotation, i.e. intrinsic representation of individual objects, is examined in two key dimensions of spatial reasoning: (1) intrinsic-static skills (e.g. recognizing, describing, classifying the spatial attributes of an object, and the relation of parts within an object); and (2) intrinsic-dynamic skills (e.g. the ability to perform rotating, folding, bending, scaling, crosssectioning the two- or three- dimensional forms or shapes). The Spatial Intelligence and Learning Center (SILC) had been working on developing measures, tests and instruments to focus on preschoolers' intrinsic spatial understanding [84]. These include measures to assess children's recognition of basic 2D and 3D geometric shapes, their comprehension of spatial terms, or ability to employ mental folding, match the shapes, rotate puzzle pieces, and find identical versus mirror images. In some of these measures, sex differences were found (i.e. Children's Mental Transformation Test, which requires to choose the right shape among multiple choices that is made of two separate pieces given in the question) [53], whereas in others socio-economic status differences occur (i.e. Test of Spatial Ability that requires copying a given target arrangement of 2D shapes or interlocking 3D blocks) [95]. The key aspect of spatial skills here is the fact that they are malleable so that both girls and boys with any kind of individual differences can improve these skills with training [92]. Then, how is it possible to train these skills?

\subsection{How to improve intrinsic spatial skills (mental rotation)?}

Early spatial experiences through materials such as block building activities, shape games, and playing with puzzles help children to develop spatial skills [96]. Children who play with more puzzles between 2 and 4 years of age have better spatial transformation abilities than their peers when they are 4.5-years-old [54]. Guided-play is considered as a scaffolding technique to promote more sustained learning with well-planned materials [27], and employing various spatial tools such as narratives and gestures improves the effectiveness of spatial instruction [22].

\subsubsection{Guided-play as a technical tool}

When delivering a content to young children, instead of direct instruction and free play, implementation of guided-play is found to be an effective learning tool, enabling child-centered exploration as well as encouraging children to become active and engaged partners in their learning process [100]. Guided play is described by Golbeck (2001) as an intermediate approach between didactic instruction and free play [27, 32]. In line with this, Ferrara et al. (2011) observed that guided play encourages parents to use more spatial language during play sessions and enable both children and parents to focus on solving specific problems related to spatial thinking [26]. Shape knowledge of 4- to 5-year-old children, as a key aspect of school readiness, is also significantly improved through guided-play when compared to free play and direct instruction [26].

\subsubsection{Narrative input as a scaffolding tool}


Language, in the form of a well-organized narration, is suggested as a powerful tool for wordto-object mapping [15]. It also helps to increase engagement in learning spatial concepts [64]. Smith (2009) pointed to a correlation between language and early visual object recognition and noted that 18 and 24 months of age is a critical period in terms of learning object names and developing object recognition. The relationships among the emergence of whole-object representation of a shape, object name learning, and goal-directed action need to be further investigated [85]. In another experimental study Casey et al. (2008) showed that incorporating a story-telling context within a block building activity has a positive impact on spatial visualization and mental rotation skills in kindergartners [16]. Therefore, ways for enriching the content of a story in a block building activity with spatial terms and concepts to further improve young children's learning are to be realized.

The Spatial Language Coding Manual [13] developed in University of Chicago (SILC) is a useful guide to analyze the content of spatial language produced by parents during play sessions. Three categories of spatial language are coded [54]: 1) dimensions, features and shapes of objects (e.g., big, small, square, triangle, curvy, straight); 2) orientation and transformation (e.g. turn it around, upside-down, flip); 3) location and direction (e.g. on, under, next to, here, there). Here, the categorization of language input presented in the manual provides an insight about what type of spatial information is required by young children in a narrative during a block building activity. Thus, this coding manual might also inform a guideline for a further narrative-based TUI design aiming to facilitate spatial learning.

\subsubsection{Gesture input as a scaffolding tool}

Gesture is another powerful tool for spatial learning, which is itself inherently spatial. It conveys meaning that is offered in the language, and highlights components of an action that promote thinking and learning of abstract ideas [34]. For instance, children at the age of 3 whose parents used more gestures when using spatial words such as dimensional adjectives (e.g. big, little, tall, short), shape terms (e.g., circle, square), and spatial features (e.g., straight, curved, bent, flat) had more spatial language than their peers whose parents gestured less [14]. Gesture (e.g., pointing) also encourages children as young as 14 months to engage or participate actively in a dialogue and to capture patterns of relationships or categories in guided activities such as joint book reading. Being involved in this interactional behavior also reinforces children's later vocabulary development [78]. In a mental transformation task, 4- and 5-year-old children who gestured more performed better in fitting two shapes together than their peers who did not gesture [22]. Furthermore, providing co-speech gestures along with spatial language is particularly effective in improving the ability to put puzzles together at the ages of 4 and 5 [104].

In most research, gestures of parents and children during play activities are coded separately $[14,78]$. Parents' gestures are coded according to their purpose: pointing to a shape in a figure or showing a rotation to help the child to engage in the process, and solve spatial problems. Moser et al. (2015) coded 2.5-3-year-old children's gestures in puzzle play activities (i.e., 3D geometric pieces on magnetic board, and 2D representations of geometric pieces on touchscreen), beginning when a piece was touched and ending when the touch ended: action 
fidelity, strategy switch, and goal efficiency (that the pieces are connected within the 2-mm threshold) [63]. We argue that the types, characteristics, and patterns of parent and child gestures in previous research can inform the design of TUIs for spatial learning.

Based on these findings in the literature, we conclude that the spatial information embedded in narratives and gestures can foster mental rotation skills of preschoolers while playing with manipulatives. Guided-play, in turn, can scaffold learning. The following sections will discuss the possible benefits of TUIs in learning and how they can be further improved by the use of narrative, gestures, and guided-play principles.

\section{TUIs for Learning as an Application Domain in Child-Computer Interaction}

\subsection{What are TUIs and why can (and should) they facilitate early spatial learning?}

As described in the previous sections, technology became an integral part of children's everyday life and digital technologies disappear or blend seamlessly into everyday objects of children such as smart boards at schools. Children as young as 2 years old are using touchbased devices to interact with digital media $[4,38]$. Ishii (2008) compared the importance of couplings between physical and digital worlds to the conjunction of sea of bits and land of atoms where the myriad of unique forms has blossomed [47]. This seashore is also regarded as a promising environment that allows children to physically interact, play, think, and learn about the world they are born into. An overview by Learning Science Research Institute highlighted that these computationally enhanced tangible interfaces may provide great opportunity especially for younger children because they allow playing with actual physical objects and these tangibles might range from being completely analogous, in the form of physical representations, to being completely digital [66]. Learning is seen as one of the major application domains of TUIs since they offer hands-on activities or manipulation of physical objects through a range of possible combinations between physical and digital representations $[5,59,66,83]$.

Marshall (2007) described a number of learning domains such as molecular biology education, programming, narrative, and dynamic systems in his analytic framework on tangibles for learning [59]. He claimed that the commonality between types of tangible interface design is that they are inherently spatial; either physically in their use of concrete manipulation, or metaphorically in their representational systems to map the interaction operations (e.g., lights, sounds or graphs in Zuckerman et al. [107, 108]). Ishii and Ullmer (1997) described TUIs in three classes: (1) Interactive Surfaces (an active interface between physical and virtual worlds), (2) Coupling of Bits and Atoms (seamless coupling of graspable everyday objects), and (3) Ambient Media (use of sound, light, airflow, and water movement for background interfaces) [46]. As a further step Van den Hoven et al. (2013) categorized the levels of physical-digital integration into three groups: (1) Discrete (a physical input and digital output are positioned vertically on a surface), (2) Collocated (physical input and digital output are positioned and displayed on a surface), (3) Embedded (the system is embedded within a physical object) [94]. The selection of examples presented in section 3.2 is based on these sets of categorizations of TUIs for learning. 
The range of possible combinations of novel links between physical action and digital representations can be one of the primary learning benefits of tangible interfaces for young children $[5,59,66]$. As also highlighted in spatial cognition literature, tangible interaction is based on physical actions with tangible physical objects that provide spatial properties (i.e., location, orientation, and configuration), and physical attributes (i.e., visual, tactile, and audio) $[5,56,63]$. Physical action such as gesturing helps young learners to extract information and learn concepts from hand movements [33] as well as demonstrating their own knowledge. The core idea of Papert's Logo turtle approach - developed in the mid-1960s is, children learn geometric shapes easier if they use their own bodies (e.g., walking a square) $[60,67,75]$. He conceived these computationally enhanced tangibles like the robot turtle as objects-to-thinkwith, in which artifacts and understanding of concepts co-evolve and help with knowledge construction in the learning process $[12,21,48,68,75]$.

Following Papert's approach, several tangible systems have been developed for children as manipulatives. Thus, the relevance of TUIs for children's spatial learning was realized long before the emergence of the term TUI [105]. The following section mainly focuses on TUI examples that combine spatial manipulatives such as wooden blocks, plastic bricks, tangram pieces with interactive surfaces and stimulate children's spatial skills.

\subsection{How TUIs can facilitate early spatial learning}

The embodiment effects of physical activity, haptic interactions with grasping and manipulating real physical objects, and the embedded computational power within physical manipulatives that the tangible technologies employ can have benefits on learning [59,66]. Some findings favor TUIs over graphical user interfaces (GUIs) with regard to children's engagement [6] and performance [102] in block building and puzzle play activities. However, the advantage of digital materials over physical materials in the context of learning is still controversial, and needs additional empirical validation $[4,109]$.

Research suggests various advantages of traditional materials over digital materials in young children's learning process such as prompting higher parent-child engagement [69], more language production in spontaneous speech [106] along with physical, sensory and metaphoric qualities of material interaction enhancing playfulness [55, 97]. Playing with traditional toys prompted more parental language both in quantity and quality than electronic toys designed to teach geometric shapes to children [106].

On the other hand, the unique capabilities of digital materials (e.g., data storage and retrieval, transportation, interactivity) allow for customized cues, prompts, and reinforcements. These functionalities, tailored to the individual have transformed the realm of education by scaffolding guided instructions and independent learning [30]. The combination of various features within the same platform (e.g., animation, game, narrative, audio or visual feedback) stimulates sensory and cognitive skills, while the challenges and feedback provided in the narrative flow enable not only active, but also minds-on engagement [40, 41]. The most commonly referred advantage of digital tools over traditional materials are their ability to provide individual experience for children [81, 96, 103, 109]. Through real-time feedback, digital tools and TUIs in particular, provide the opportunity to iterate action with reflection-on-action to enhance 
leaning [40]. So far, the advantage of TUIs compared to other materials is implied in the function and representation of physical objects in an application, so that the conventional toys can be used as controllers of interactive games [57]. However, more empirical research is needed to investigate the impact of TUIs on learning, especially compared to the use of nondigital physical materials.

Given that both physical interaction with traditional materials and digitally enhanced interactive tools carry advantages and challenges for preschoolers, then what would be the benefits of TUIs which synthesize both platforms to favor spatial skills in particular? As discussed in the previous section, children benefit more from playing with spatial manipulatives if they are guided by a narrative and gesture during block building activities [15, 22, 104]. There are different narrative and gesture-based examples of TUIs. Thus, the following subsections will present the examples of TUIs to understand how narrative and gesture input might be augmented in TUI design to scaffold young children's spatial reasoning.

\subsubsection{Narrative-based TUIs for learning}

A story-telling context as a narrative device has a positive impact on preschoolers' spatial visualization, construction, and rotation skills when incorporated into block building activities [15]. Storytelling is also a typical learning domain that TUIs might enhance because the structure of narrative includes a sequence of events [59] and helps children to organize the information they receive. By representing the temporal sequence of events in a narrative in a spatial format [59], much of the activities in TUIs for learning involves interactive storytelling $[44,66]$. Preschool children often engage in tangible storytelling by using physical artefacts in their immediate environment to create their own stories. Some projects in TUI have taken advantage of this physical aspect of storytelling [44]. For example, Holmquist and colleagues (2000) invented a design for interactive storytelling that allowed users to experience different parts of a story by manipulating physical objects. As such, the boundary between story and interface was blurred [42].

TUI projects based on storytelling include various aspects such as tangible characters (e.g., KidStory [87], TellTale [2]), room-sized ambient storytelling environments (e.g., Storyrooms [1], Pogo World [77]), interactive surfaces (e.g., StoryMat [79], KidPad [44], LinguaBytes [39]), tangible word blocks (e.g., RoyoBlocks [50]), audio-video or motion recorders (e.g., Tangicam [51], I/O Brush [80], Jabberstamp [72]), and storytelling robots (e.g., PETS [20]). However, as Tanenbaum et al. (2010) emphasized tangible storytelling technology often focuses on mapping tangible objects for system outcome rather than focusing on the narrative meaning of the objects itself [89]. Hereby, Make a Riddle by Sifteo Inc. [45] is an efficient example for the use of a physical object as an embedded TUI. It is a hybrid tangible-graphical interface that teaches children spatial language (i.e., prepositions) in rhymes through manipulating Sifteo Cubes. In turn, it provides responsive narrative feedback to related motions. When delivering spatial concepts in the form of a narrative, physical objects might help young children connect with the content more readily. Thus, investigating how manipulatives can be enhanced digitally to understand a spatial content easier might illuminate the tangible interaction research and user studies on young children. 


\subsubsection{Gesture-based TUIs for learning}

Gesture-based examples of TUIs are accounted to support children's learning and reasoning [5]. Spatial problem solving, which involves hands-on action, manipulation and mental rotation skills, is addressed as one of the important knowledge gaps in tangible interaction research [4, 43]. There are a few gesture-based tangible prototypes that relate to spatial skills. TICLE [82] for instance is an archetype that combines physical tangram puzzle play with an interactive tabletop. Curlybot [29], a programmable curved object, and Topobo [71], a construction kit with modular block building system, are two examples of TUIs that capture physical motion and create a playful robot experience for children. However, to date, knowledge about how and to what extent children's spatial learning benefits from these TUIs is lacking.

The use of manipulatives (physical objects) in teaching and learning, especially during the preschool period has a long history [31, 62]. Fröbel and Montessori introduced manipulatives as physical modeling of abstract structures related to spatial reasoning designed to foster preschoolers' learning. Resnick and colleagues (1998) translated Fröbel's and Papert's approaches into Digital Manipulatives that enable children to explore mathematical and scientific concepts (e.g., numbers and shapes) through direct manipulation of computationally enhanced physical objects (e.g., blocks, balls, beads, badges) [76]. Fröbel Gifts and Montessori materials furthermore inspired the development of well-known products for children that dominate the market (e.g., wooden blocks, plastic bricks, Lego Mindstorms ${ }^{\circledR}$, Tinkertoy ${ }^{\circledR}$, Zome ${ }^{\circledR}$, Base Ten Blocks ${ }^{\circledR}$, Cuisenaire Rods ${ }^{\circledR}$, Fraction Tiles ${ }^{\circledR}$, Wikki Stix $\left.{ }^{\circledR}\right)$ [108]. Zuckerman and his colleagues, in turn, extended the work of Fröbel and Montessori by developing an interface design with computationally enhanced building blocks $[76,108]$. Their work introduced a new classification by situating the use of such manipulatives to encourage hands-on modeling of abstract structures for children above 7 years old [108]. This approach can serve as a basis for further interpretations tailored to the needs and abilities of preschoolers' physical actions and behaviors in play activities with spatial manipulatives.

\subsubsection{Manipulatives that might be used in further TUI design for spatial learning}

A recent study argued that both canonical and non-canonical shape materials on the market today are inadequate in providing variety for preschoolers in terms of inviting comparison and contrast of different versions of shapes from different categories [74]. Similarly, Verdine et al. (2014) state that most of the research that employed spatial materials in investigating the mental rotation skills of preschoolers is based on building blocks and jigsaw puzzles. However, the use of other types of manipulatives for this age range is yet to be investigated [96]. In addition, TUIs inspired by analogue building blocks (e.g., Algo Blocks [88], Lego Wall [28], mediaBlocks [90], Electronic Blocks [101], Topobo [71], Boda Blocks [11], LittleBits [8] etc.), generally receive more attention in the literature [91].

Clements (1998) suggested that manipulatives such as tangrams, pattern blocks, and other sets of shapes can provide a foundation to build imagery for young children and aid spatial visualization. This includes understanding and performing imagined movements of two- and three-dimensional objects $[17,18]$. Thus, we point to the manipulatives that afford different scales and sizes of different shapes such as tangram [23] (see Figure 1) or Fröbel Gifts [86] (see 
Figure 2) that enable a wide range of figure configurations. A preliminary study indicated that the narrative context helps children's coherence of abstract tangram figures, and triggers rotation of geometric tangram pieces, in particular, between 28 and 36 months of age [7]. Hence, tangrams can also be used for promoting younger children's spatial understanding and abstract concepts.
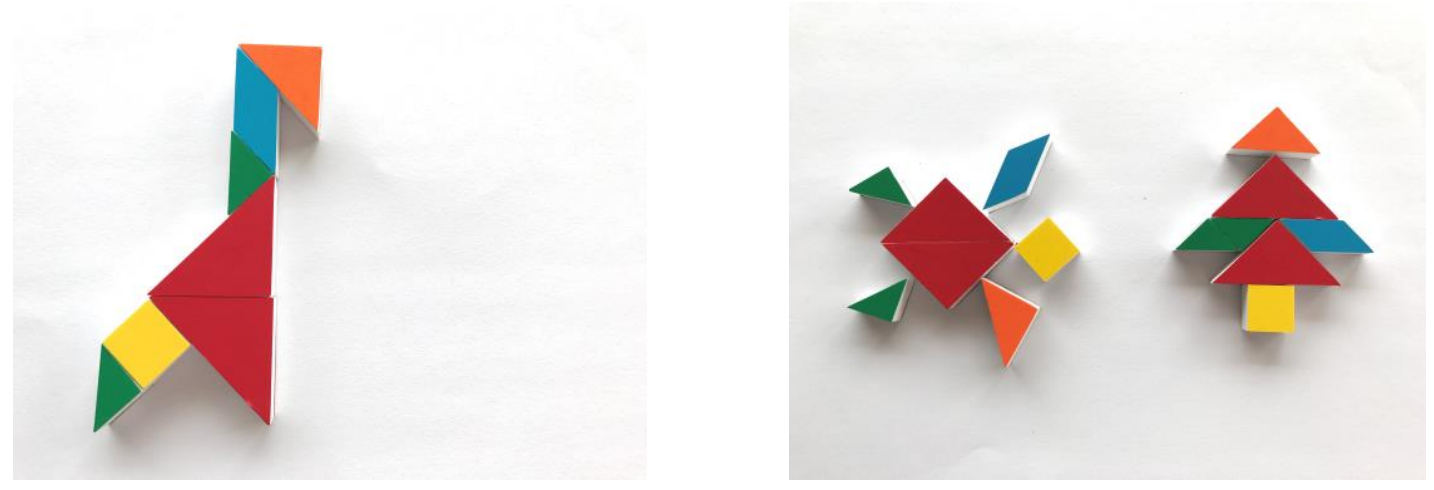

Figure 1. Examples for figure configurations with tangram

Here we put emphasis on Fröbel's Gifts (see Figure 2) not only because they are overlooked manipulatives but also, they are directly linked to spatial learning that can favor a child-centered TUI design [49, 108]. Friedrich Fröbel, a German pedagogue and education philosopher who lived in the first half of the 19th century, introduced a child-centered approach to education. He coined the term "kindergarten" as a place where children are helped to acquire knowledge about the world through physical objects, and about spatial relations through holding, dropping, rolling, swinging, hiding, and revealing [86]. He developed educational toys that help children to make sense of the world through primitive objects, which are known as Fröbel's Play Gifts. His approach was an important milestone in realizing children's active role in learning, in particular, spatial learning. Central in Fröbel's approach is children's hands-on interaction with manipulatives. These manipulatives in primitive forms help children to make sense of this threedimensional world (i.e., space), which, according to Fröbel, is our native environment as human beings. His aim was to facilitate young children's abstract thinking and encourage them to build associations between these primitive forms and the concrete world. The primitive forms consist of ball (sphere), cube, cylinder, surface (tablet), line (rectilineal sticks and curvilineal rings), and point (beads) to form different series that help children to think about shape, pattern, and space [86]. 

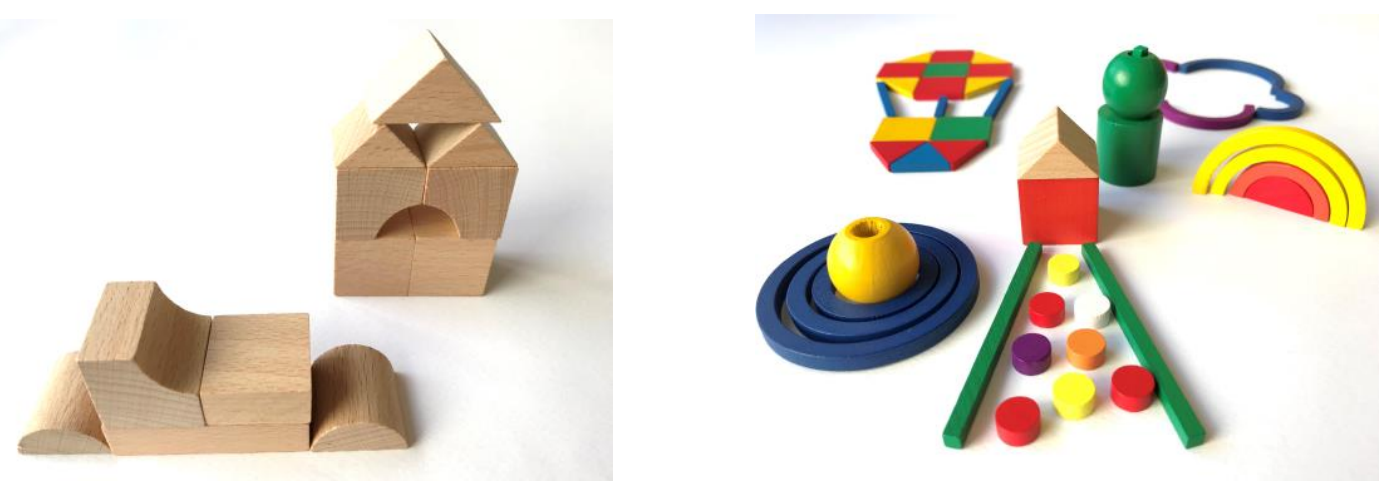

Figure 2. Examples for figure configurations with Fröbel Gifts

Spatial manipulatives such as tangram and Fröbel Gifts allow mental rotation actions inviting children to practice static skills (recognizing, categorizing, and classifying objects) and dynamic skills (rotating, scaling, bending, cross-sectioning objects). In addition, these manipulatives are suitable for creating different figure configurations that can be integrated in narratives and tasks. The scaffolding effect of storytelling can help disambiguate young children's interpretation of how to interact with spatial manipulatives as tangible representations. While enriching spatial visualization, these materials would also provide more variety in spatial properties of objects such as location and orientation embedded in the figure configurations. This will eventually encourage young children to think and act more on mental rotation strategies that require static and dynamic skills.

Some recent works or projects in the industry use physical objects combined with digital tools that trigger spatial thinking. Most of them do not explicitly aim to facilitate mental rotation skills but rather provide children an alternative way of experience for the spatiality of reading a story book (e.g., Bridging Book, and BooksARalive), programming skills to employ navigational skills and spatial language (e.g., Dash and Dot, and Puzzlets), or learning mathematics at early ages by using hands (e.g., Little Digits). A few of them enhance the use of physical block building activities (e.g., Osmo Tangram, Koski Game) and integrate storytelling as well (e.g., Magik Bricks). These works exemplify the combined use of physicaldigital materials in technology and how they would expand opportunities for children to employ various spatial learning experiences in different settings while making connections among information in a specific context. However, most of these tools target children older than 4year-olds. There is still little evidence on interactive products for very young children younger than 4 years of age as well as a suitable model for design process evaluating children as active users, players, learners, testers, informants, and design partners [21, 58].

In the following section we discuss our insights on the review of two research areas and also review some of the few child-centered design methods adapted or modified to involve children as young as 3 and 4 years of age into design.

\section{Discussing Current Gaps to Bridge Two Disciplines}

This paper presented an overview of research that combines empirical findings along with the current stand in children's spatial learning theories and in research about the current state of 
TUI for learning. The two areas of studies are based on the goal for extracting knowledge about how young children think and behave while playing or interacting with tangible physical objects (manipulatives) that have spatial properties (i.e., location, orientation, and configuration) and physical attributes (i.e., visual, tactile, and audio) [5, 57, 63]. Both fields investigate children's interactions with manipulatives, mainly using block building activities. Both research areas found narrative and gesture-based tools as scaffolding the learning process of very young children, and developed technical systems and methods by making use of these tools. Here we propose the following framework as a theoretical ground for bridging two research areas. The framework illustrates the complementary nature of two fields in terms of their constructive approach to learning, the integrative scaffolding and technical tools, and goals defined for future work (see Figure 3).

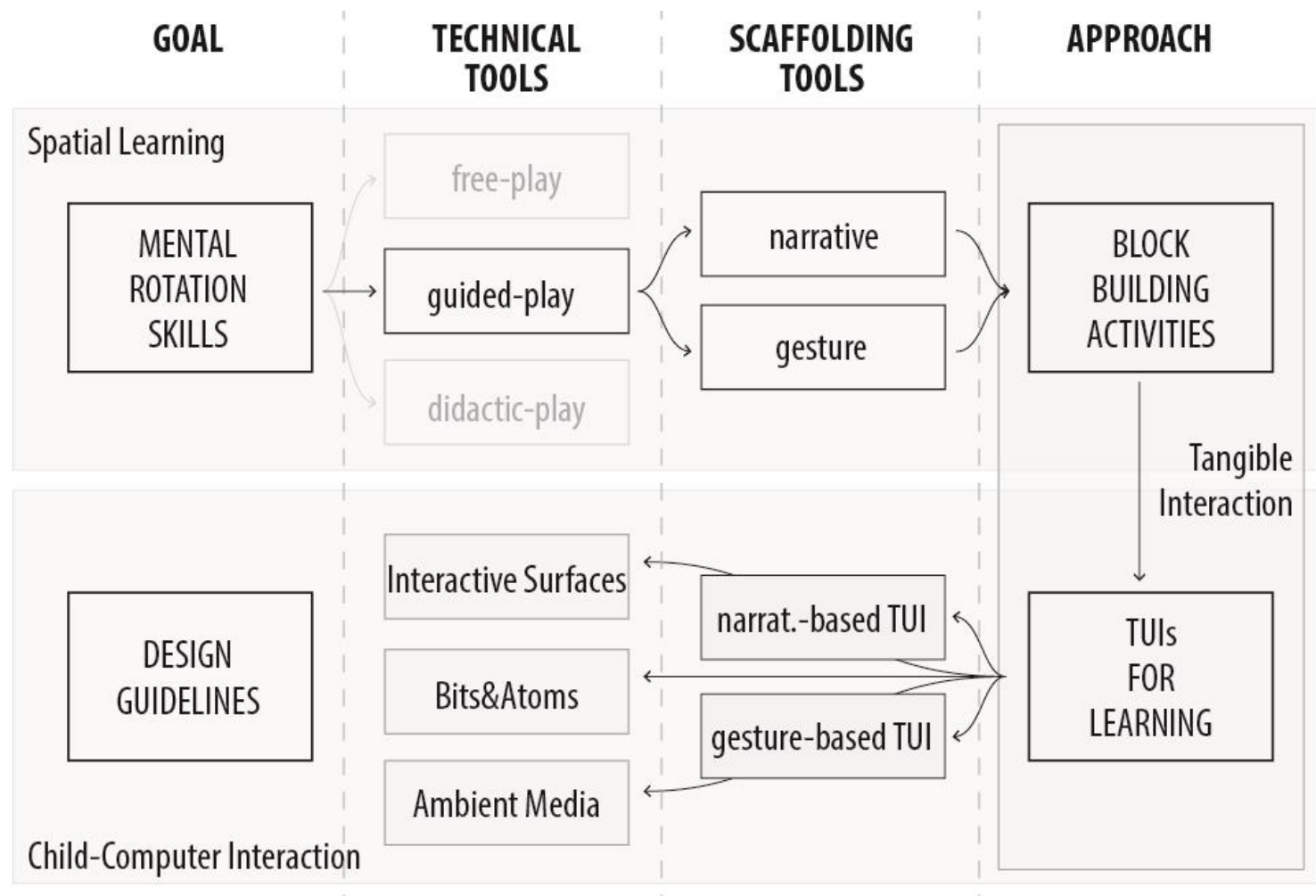

Figure 3. Two complementary research areas: Spatial learning of very young children and TUI design for learning.

To explore ways to make both fields' goals meet each other actively, it would be meaningful to look at design methods conducted with children under 4 years old. Although there is a growing concern in generating methods for involving children in the design process since 1980s [21, 37, 58], we have not encountered a design method specifically customized for children younger than 4 years of age $[9,10,24]$. We found very few adapted cooperative and participatory design methods with children. Since most child-centered methods rely on the cooperative evaluations and verbalization techniques (e.g., interviews, diary keeping, questionnaires), young children have not been directly involved in design process [56]. This is mostly because young children are less able to read, write, verbalize their thoughts, and concentrate on a task easily [56]. An initial effort by Farber et al., (2002) was to modify Druin's influential Cooperative Inquiry [19] for including children between 4-6 years old [25]. Later, with a similar attempt Guha and her colleagues' developed Mixing Ideas technique conducted with children as young as 3 years old 
[36]. The lessons learned through these studies showed that young children need more structured design sessions to cooperate, rather work one-on-one in a team, and can employ drawing and cutting-pasting activities to communicate their thoughts [36].

Marco and his colleagues (2013) emphasized that young children are active users of technology and thus entitled to be involved in user-centered design projects [57]. They recruited children between 3 and 6 years of age to the design of a collocated TUI system design. They reported how they used Wizard of Oz method to observe elicited gestures and Peer Tutoring for guiding narrative expressions required by child users. They concluded that the physical nature of tangible technologies fits this very young user profile to retrieve information from their user actions when playing with toys [57]. These studies showed that observational method involving children under 4 years old as users has been the most convenient child-centered design method so far for working with this challenging age group.

What Fröbel and Papert had in common was that they both began with observing children to understand the nature of the learning process, and helped children in the heuristics of playing with manipulatives as objects-to-think-with. Today, researchers both in TUI and developmental studies trace the observational path to understand actions, manipulations, and rotation strategies elicited from even younger children's interaction with physical objects. Hereby we argue that, spatial manipulatives not only allow learners to practice mental rotation actions but also enable producing different figures to be integrated in narratives and tasks. Therefore, they can also serve well as low-tech, child-friendly supplies for prototyping to design high tech applications. Since designers or researchers might have difficulty in communicating with children between 2 and 4 years old, such story-based tasks designed with manipulatives [7] might be helpful for involving children in interactional behavior, actively engaging them in a dialogue, and more effectively including them in the design process. The outputs of the experimental designs produced with these manipulatives will also contribute to the current state of the field by providing information about young children's experiences in user studies. Understanding how these facilitating mechanisms of spatial learning work in young children's experiences with different types of manipulatives would inform research on exploring and designing necessary components for playful environments.

Based on the reviewed literature, we can conclude that observing young children's interactions with spatial manipulatives in goal-directed mental rotation tasks in the form of guided-play might be helpful for modifying current methods found in design research, as well as informing narrative and gesture-based tangible systems. Also, methods used to code gestures and narratives used in cognitive developmental studies might also be helpful for providing empirical definitions and analysis elicited from these observational methods. We hope this paper contributes to child-centered user research methods and design studies by presenting information about user needs of children between 2 and 4 years of age, and invite research that explores ways to facilitate spatial learning related to STEAM skills such as mental rotation.

\section{Conclusion}

Bridging between two disciplines, a series of potential opportunities appear both for early spatial learning theories and TUIs, which in turn might facilitate young children's spatial skills. 
First, integrating and implementing the reliable intervention techniques and tools suggested in research on spatial learning might also yield an understanding of young children's spatial learning into physical-digital interaction. Second, developing reliable methods in child-centered design practices involving children younger than 4-year-olds might fill an important gap while providing evaluation constructs and measures. Third, bringing out formative evaluations and prescriptive guidance based on observational research that can be used to inform the design through case studies would ensure empirically validated design choices. Fourth, observing children's physical-digital interactions with spatial manipulatives would provide in-depth insights into their learning patterns as well as their user behaviors and thinking strategies. Finally, generating empirical support to elaborate the proposed claims and expanding the opportunities for preschool children's spatial experiences would also open new horizons in future research on the learning benefits of TUIs.

TUIs are constructive, relational and associative systems that bring physical and digital affordances together. TUI learning environments may therefore be helpful in the context of spatial learning. Thus, our aim is to emphasize the importance of producing knowledge and evidence-based tools to facilitate young children's spatial skills, and highlight some of the opportunities for further studies in both areas. As more research is conducted in both areas, more explorations will elicit specificity in theoretically grounded TUI design that is supportive of spatial learning.

\section{References}

1. Alborzi, H., Druin, A., Montemayor, J., Platner, M., Porteous, J., Sherman, L., \& Kruskal, A. (2000, August). Designing StoryRooms: interactive storytelling spaces for children. In Proceedings of the 3rd conference on Designing interactive systems: processes, practices, methods, and techniques (pp. 95-104). ACM.

2. Ananny, M. (2002, January). Supporting children's collaborative authoring: practicing written literacy while composing oral texts. In Proceedings of the Conference on Computer Support for Collaborative Learning: Foundations for a CSCL Community (pp. 595-596). International Society of the Learning Sciences.

3. Antle, A. N. (2007, February). The CTI framework: informing the design of tangible systems for children. In Proceedings of the 1st international conference on Tangible and embedded interaction (pp. 195-202). ACM.

4. Antle, A. N. (2012, October). Knowledge gaps in hands-on tangible interaction research. In Proceedings of the 14th ACM international conference on Multimodal interaction (pp. 233-240). ACM.

5. Antle, A. N., \& Wise, A. F. (2013). Getting down to details: Using theories of cognition and learning to inform tangible user interface design. Interacting with Computers, 25(1), 1-20.

6. Antle, A. N. (2013). Exploring how children use their hands to think: An embodied interactional analysis. Behaviour \& Information Technology, 32(9), 938-954. 
7. Baykal, G. E., Alaca, I. V., Yantaç, A. E., \& Göksun, T. (2016, June). Developing Transmedia Puzzle Play to Facilitate Spatial Skills of Preschoolers. In Proceedings of the The 15th International Conference on Interaction Design and Children (pp. 631-636). ACM.

8. Bdeir, A., \& Richardson, M. (2015). Getting Started with littleBits: Prototyping and Inventing with Modular Electronics. Maker Media, Inc..

9. $\quad$ Borum, N., Brooks, E. P., \& Brooks, A. L. (2015). Designing with Young Children. Design, User Experience, and Usability: Interactive Experience Design Lecture Notes in Computer Science.

10. Bruckman, A., Bandlow, A., \& Forte, A. (2009). HCI for Kids. In (eds. Sears, A. and Jacko, J.A.) Human-Computer Interaction: Designing for Diverse Users and Domains. Boca Raton, FL: CRC Press, pp. 793-808.

11. Buechley, L., \& Eisenberg, M. (2007, July). Boda blocks: a collaborative tool for exploring tangible three-dimensional cellular automata. In Proceedings of the 8th iternational conference on Computer supported collaborative learning (pp. 102104). International Society of the Learning Sciences.

12. Bull, G. (2009). Tutor, Tool, Tutee: A Vision Revisited. Contemporary Issues in Technology and Teacher Education, 9(2), 89-94.

13. Cannon, J., Levine, S., \& Huttenlocher, J. (2007). A system for analyzing children and caregivers' language about space in structured and unstructured contexts. Spatial Intelligence and Learning Center (SILC) technical report.

14. Cartmill, E., Pruden, S. M., Levine, S. C., Goldin-Meadow, S., \& Center, S. I. L. (2010). The role of parent gesture in children's spatial language development. In Proceedings of the 34th Annual Boston University Conference on Language Development, 70-77.

15. Casey, B. M., Andrews, N., Schindler, H., Kersh, J. E., Samper, A., \& Copley, J. (2008a). The development of spatial skills through interventions involving block building activities. Cognition and Instruction, 26(3), 269-309.

16. Casey, B., Erkut, S., Ceder, I., \& Young, J. M. (2008b). Use of a storytelling context to improve girls' and boys' geometry skills in kindergarten. Journal of Applied Developmental Psychology, 29(1), 29-48.

17. Clements, D. H. (1998). Geometric and Spatial Thinking in Young Children. Educational Resources Information Center. VA: Arlington.

18. Clements, D. H., \& Sarama, J. (2007). Effects of a preschool mathematics curriculum: Summative research on the Building Blocks project. Journal for Research in Mathematics Education, 136-163.

19. Druin, A. (1999). Cooperative inquiry: developing new technologies for children with children. In Proceedings of the SIGCHI conference on Human Factors in Computing Systems (pp. 592-599). ACM.

20. Druin, A., Montemayor, J., Hendler, J., McAlister, B., Boltman, A., Fiterman, E., Plaisant, A., Kruskal, A., Olsen, H., Revett, I., Schwenn, T.P., Sumida, L., \& Wagner, R. (1999, May). Designing PETS: A personal electronic teller of stories. In Proceedings of the SIGCHI conference on Human Factors in Computing Systems (pp. 326-329). ACM. 
21. Druin, A. (2002). The role of children in the design of new technology. Behaviour and information technology, 21(1), 1-25.

22. Ehrlich, S. B., Levine, S. C., \& Goldin-Meadow, S. (2006). The importance of gesture in children's spatial reasoning. Developmental psychology, 42(6), 1259.

23. Elffers, J. (1976). Tangram: The ancient Chinese shapes game. New York, USA: Penguin Books.

24. Fails, J. A., Guha, M. L., \& Druin, A. (2012). Methods and techniques for involving children in the design of new technology for children. Human-Computer Interaction, 6(2), 85-166.

25. Farber, A., Druin, A., Chipman, G., Julian, D., \& Somashekher, S. (2002, January). How Young Can Our Technology Design Partners Be?. In PDC (pp. 272-277).

26. Ferrara, K., Hirsh-Pasek, K., Newcombe, N. S., Golinkoff, R. M., \& Lam, W. S. (2011). Block talk: Spatial language during block play. Mind, Brain, and Education, 5(3), 143-151.

27. Fisher, K. R., Hirsh-Pasek, K., Newcombe, N., \& Golinkoff, R. M. (2013). Taking shape: Supporting preschoolers' acquisition of geometric knowledge through guided play. Child development, 84(6), 1872-1878.

28. Fitzmaurice, G. (1996). Graspable User Interfaces, Ph.D. thesis, University of Toronto, Toronto (1996).

29. Frei, P., Su, V., Mikhak, B., \& Ishii, H. (2000, April). Curlybot: designing a new class of computational toys. In Proceedings of the SIGCHI conference on Human factors in computing systems (pp. 129-136). ACM.

30. Frey, N., Fisher, D., \& Gonzalez, A. (2013). Teaching with Tablets: How do I integrate tablets with effective instruction? Alexandria, VA: ASCD Arias.

31. Fröbel, F. (1826). On the Education of Man (Die Menschenerziehung). Keilhau/Leipzig: Wienbrach.

32. Golbeck, S. L. (2001). Instructional models for early childhood: In search of a childregulated/teacher-guided pedagogy. Psychological perspectives on early childhood education: Reframing dilemmas in research and practice, 3-34.

33. Goldin-Meadow, S., Cook, S. W., \& Mitchell, Z. A. (2009). Gesturing gives children new ideas about math. Psychological Science, 20(3), 267-272.

34. Goldin-Meadow, S. (2015). From action to abstraction: Gesture as a mechanism of change. Developmental Review, 38, 167-184.

35. Göksun, T. and Özer, D. (2016). Spatial Cognition. In Ç. Aydın, T. Göksun, A. Küntay, \& D. Tahiroğlu (Eds.), Handbook of Cognitive Development, Istanbul, Koç University Press (in Turkish).

36. Guha, M. L., Druin, A., Chipman, G., Fails, J. A., Simms, S., \& Farber, A. (2004, June). Mixing ideas: a new technique for working with young children as design partners. In Proceedings of the 2004 conference on Interaction design and children: building a community (pp. 35-42). ACM.

37. Guha, M. L., Druin, A., \& Fails, J. A. (2013). Cooperative Inquiry revisited: Reflections of the past and guidelines for the future of intergenerational codesign. International Journal of Child-Computer Interaction, 1(1), 14-23.

38. Gutnick, A. L., Robb, M., Takeuchi, L., \& Kotler, J. (2010). Always connected: The new digital media habits of young children. New York: The Joan Ganz Cooney Center at Sesame Workshop. 
39. Hengeveld, B., Voort, R., Hummels, C., de Moor, J., van Balkom, H., Overbeeke, K., \& van der Helm, A. (2008). The development of LinguaBytes: an interactive tangible play and learning system to stimulate the language development of toddlers with multiple disabilities. Advances in Human-Computer Interaction, 2008, 1.

40. Hinske, S., Langheinrich, M., \& Lampe, M. (2008, February). Towards guidelines for designing augmented toy environments. In Proceedings of the 7th ACM conference on Designing interactive systems (pp. 78-87). ACM.

41. Hirsh-Pasek, K., Zosh, J. M., Golinkoff, R. M., Gray, J. H., Robb, M. B., \& Kaufman, J. (2015). Putting Education in "Educational" Apps Lessons From the Science of Learning. Psychological Science in the Public Interest, 16(1), 3-34.

42. Holmquist, L. E., Helander, M., \& Dixon, S. (2000). Every object tells a story: Physical interfaces for digital storytelling. In Proceedings of the NordiCHI.

43. Hourcade, J. P., Revelle, G., Zeising, A., Iversen, O. S., Pares, N., Bekker, T., \& Read, J. C. (2016, May). Child-Computer Interaction SIG: New Challenges and Opportunities. In Proceedings of the 2016 CHI Conference Extended Abstracts on Human Factors in Computing Systems (pp. 1123-1126). ACM.

44. Hourcade, J. P., Bederson, B. B., Druin, A., \& Taxén, G. (2002, April). KidPad: collaborative storytelling for children. In $\mathrm{CHI}^{\prime} \mathrm{O} 2$ extended abstracts on Human factors in computing systems (pp. 500-501). ACM.

45. Hunter, S., Kalanithi, J., \& Merrill, D. (2010, June). Make a Riddle and TeleStory: designing children's applications for the siftables platform. In Proceedings of the 9th International Conference on Interaction Design and Children (pp. 206-209). ACM.

46. Ishii, H., \& Ullmer, B. (1997, March). Tangible bits: towards seamless interfaces between people, bits and atoms. In Proceedings of the ACM SIGCHI Conference on Human factors in computing systems (pp. 234-241). ACM.

47. Ishii, H. (2008, February). Tangible bits: beyond pixels. In Proceedings of the 2 nd international conference on Tangible and embedded interaction (pp. xv-xxv). ACM.

48. Kafai, Y. B., \& Resnick, M. (1996). Constructionism in practice: Designing, thinking, and learning in a digital world. New Jersey, USA: Lawrence Erlbaum Associates, Publishers.

49. Kafai, Y. B., Peppler, K. A., Burke, Q., Moore, M., \& Glosson, D. (2010, June). Fröbel's forgotten gift: textile construction kits as pathways into play, design and computation. In Proceedings of the 9th International Conference on Interaction Design and Children (pp. 214-217). ACM.

50. Kleiman, J., Pope, M., \& Blikstein, P. (2013, June). RoyoBlocks: An exploration in tangible literacy learning. In Proceedings of the 12th International Conference on Interaction Design and Children (pp. 543-546). ACM.

51. Labrune, J. B., \& Mackay, W. (2005, June). Tangicam: exploring observation tools for children. In Proceedings of the 2005 conference on Interaction design and children (pp. 95-102). ACM.

52. Lauer, J. E., \& Lourenco, S. F. (2016). Spatial Processing in Infancy Predicts Both Spatial and Mathematical Aptitude in Childhood. Psychological Science, 0956797616655977.

53. Levine, S. C., Huttenlocher, J., Taylor, A., \& Langrock, A. (1999). Early sex differences in spatial skill. Developmental psychology, 35(4), 940. 
54. Levine, S. C., Ratliff, K. R., Huttenlocher, J., and Cannon, J. (2012). Early puzzle play: a predictor of preschoolers' spatial transformation skill. Developmental Psychology, 48(2), 530.

55. Mackey, M. (2008). Postmodern Picturebooks and the Material Conditions of Reading. In Sipe, L.R \& Pantaleo, S. (Eds.) Postmodern Picturebooks: Play, Parody and Self Referentiality. New York: Routledge, 103-16.

56. Marco, J., Cerezo, E., Baldassarri, S., Mazzone, E., \& Read, J. C. (2009, September). Bringing tabletop technologies to kindergarten children. In Proceedings of the 23rd British HCI Group Annual Conference on People and Computers: Celebrating People and Technology (pp. 103-111). British Computer Society.

57. Marco, J., Cerezo, E., \& Baldassarri, S. (2013). Bringing tabletop technology to all: evaluating a tangible farm game with kindergarten and special needs children. Personal and ubiquitous computing, 17(8), 1577-1591.

58. Markopoulos, P., Read, J. C., MacFarlane, S., \& Hoysniemi, J. (2008). Evaluating children's interactive products: principles and practices for interaction designers. Burlington, MA: Morgan Kaufmann Publishers.

59. Marshall, P. (2007, February). Do tangible interfaces enhance learning?. In Proceedings of the 1st international conference on Tangible and embedded interaction (pp. 163-170). ACM.

60. McNerney, T. S. (2004). From turtles to Tangible Programming Bricks: explorations in physical language design. Personal and Ubiquitous Computing, 8(5), 326-337.

61. Montello, D. R., Grossner, K. E., \& Janelle, D. G. (2014). Concepts for Spatial Learning and Education: An Introduction. Space in Mind: Concepts for Spatial Learning and Education. Cambridge, MA: The MIT Press.

62. Montessori, M. (1916). English translation (2004). In Gutek, L.G. (Ed.) The Montessori Method: the origins of an educational innovation, including an abridged and annotated edition of Maria Montessori's The Montessori method. Lanham, USA: Rowman \& Littlefield Publishers, Inc.

63. Moser, A., Zimmermann, L., Dickerson, K., Grenell, A., Barr, R., \& Gerhardstein, P. (2015). They can interact, but can they learn? Toddlers' transfer learning from touchscreens and television. Journal of experimental child psychology, 137, 137-155.

64. Nachtigäller, K., Rohlfing, K. J., \& McGregor, K. K. (2013). A story about a word: does narrative presentation promote learning of a spatial preposition in German twoyear-olds?. Journal of child language, 40(04), 900-917.

65. Newcombe, N. S., Uttal, D. H., \& Sauter, M. (2013). Spatial Development. (Ed.) Zelazo, P. The Oxford Handbook of Developmental Psychology, Vol.1: Body and Mind. Oxford Univesity Press.

66. O’Malley, C., and Stanton Fraser, D. (2004). Literature Review in Learning with Tangible Tecnologies. Technical Report 12, NESTA Futurelab. Retrieved on 22 May 2016, from: http://www.nfer.ac.uk/publications/FUTL69/FUTL69.pdf

67. Papert, S. (1980). Mindstorms: Children, computers, and powerful ideas. Basic Books, Inc.

68. Papert, S. (1993). The children's machine: Rethinking School in the Age of Computer. New York: BasicBooks.

69. Parish-Morris, J., Mahajan, N., Hirsh-Pasek, K., Golinkoff, R. M., \& Collins, M. F. (2013). Once upon a time: Parent-child dialogue and storybook reading in the electronic era. Mind, Brain, and Education, 7(3), 200-211. 
70. Ping, R., Ratliff, K., Hickey, E., \& Levine, S. C. (2011). Using manual rotation and gesture to improve mental rotation in preschoolers. In Proceedings of the XXXIV annual meeting of the cognitive science society.

71. Raffle, H. S., Parkes, A. J., \& Ishii, H. (2004, April). Topobo: a constructive assembly system with kinetic memory. In Proceedings of the SIGCHI conference on Human factors in computing systems (pp. 647-654). ACM.

72. Raffle, H., Vaucelle, C., Wang, R., \& Ishii, H. (2007, June). Jabberstamp: embedding sound and voice in traditional drawings. In Proceedings of the 6th international conference on Interaction design and children (pp. 137-144). ACM.

73. Read, J. C., \& Markopoulos, P. (2013). Child-Computer Interaction. International Journal of Child-Computer Interaction, 1(2013), 2-6.

74. Resnick, I., Verdine, B. N., Golinkoff, R., \& Hirsh-Pasek, K. (2016). Geometric toys in the attic? A corpus analysis of early exposure to geometric shapes. Early Childhood Research Quarterly, 36, 358-365.

75. Resnick, M. (1997). Turtles, termites, and traffic jams: Explorations in massively parallel microworlds. Cambridge, MA: MIT Press.

76. Resnick, M., Martin, F., Berg, R., Borovoy, R., Colella, V., Kramer, K., \& Silverman, B. (1998). Digital manipulatives: new toys to think with. In Proceedings of the SIGCHI conference on Human factors in computing systems (pp. 281-287). ACM Press/Addison-Wesley Publishing Co.

77. Rizzo, A., Marti, P., Decortis, F., Rutgers, J., \& Thursfield, P. (2003). Building narrative experiences for children through real time media manipulation: POGO World. In Funology (pp. 189-199). Springer Netherlands.

78. Rohlfing, K. J. (2005). Learning prepositions. Perspectives on Language Learning and Education, 12(3), 13-17.

79. Ryokai, K., \& Cassell, J. (1999, May). StoryMat: a play space for collaborative storytelling. In CHI'99 extended abstracts on Human factors in computing systems (pp. 272-273). ACM.

80. Ryokai, K., Marti, S., \& Ishii, H. (2004, April). I/O brush: drawing with everyday objects as ink. In Proceedings of the SIGCHI conference on Human factors in computing systems (pp. 303-310). ACM.

81. Sargeant, B. (2015). What is an ebook? What is a book app? And why should we care? An analysis of contemporary digital picture books.Children's Literature in Education, 46(4), 454-466.

82. Scarlatos, L. L. (2002). TICLE: using multimedia multimodal guidance to enhance learning. Information Sciences, 140(1), 85-103.

83. Shaer, O., \& Hornecker, E. (2010). Tangible user interfaces: past, present, and future directions. Foundations and Trends in Human-Computer Interaction, 3(1-2), 1-137.

84. SILC (Spatial Intelligence and Learning Center). Tests and Instruments. Retrieved on 22 May 2016, from http://spatiallearning.org/index.php/resources/testsainstruments

85. Smith, L. B. (2009). From fragments to geometric shape changes in visual object recognition between 18 and 24 months. Current Directions in Psychological Science, 18(5), 290-294.

86. Snider, D. J. (1900). The Psychology of Froebel's Play-gifts. Chicago, ILLS: Sigma Publishing Co.

87. Stanton, D., O'Malley, C., Bayon, V., Hourcade, J. P., Sunblad, Y., Fast, C., ... \& Benford, S. (2004). The KidStory project: developing collaborative storytelling tools for children, with children. 
88. Suzuki, H., \& Kato, H. (1993, August). AlgoBlock: a tangible programming language, a tool for collaborative learning. In Proceedings of 4th European Logo Conference (pp. 297-303).

89. Tanenbaum, J., Tanenbaum, K., \& Antle, A. (2010, April). The Reading Glove: designing interactions for object-based tangible storytelling. In Proceedings of the 1st Augmented Human International Conference (p. 19). ACM.

90. Ullmer, B., Ishii, H., \& Glas, D. (1998, July). mediaBlocks: physical containers, transports, and controls for online media. In Proceedings of the 25th annual conference on Computer graphics and interactive techniques (pp. 379-386). ACM.

91. Ullmer, B., \& Ishii, H. (2000). Emerging frameworks for tangible user interfaces. IBM systems journal, 39(3.4), 915-931.

92. Uttal, D. H., Meadow, N. G., Tipton, E., Hand, L. L., Alden, A. R., Warren, C., \& Newcombe, N. S. (2013a). The malleability of spatial skills: a meta-analysis of training studies. Psychological bulletin, 139(2), 352.

93. Uttal, D. H., Miller, D. I., \& Newcombe, N. S. (2013b). Exploring and enhancing spatial thinking links to achievement in science, technology, engineering, and mathematics? Current Directions in Psychological Science, 22(5), 367-373.

94. van den Hoven, E., van de Garde-Perik, E., Offermans, S., van Boerdonk, K., \& Lenssen, K. M. H. (2013). Moving Tangible Interaction Systems to the Next Level. IEEE Computer, 46(8), 70-76.

95. Verdine, B. N., Golinkoff, R. M., Hirsh-Pasek, K., Newcombe, N. S., Filipowicz, A. T., \& Chang, A. (2013). Deconstructing building blocks: Preschoolers' spatial assembly performance relates to early mathematical skills. Child development, 85(3), 1062-1076.

96. Verdine, B. N., Golinkoff, R. M., Hirsh-Pasek, K., \& Newcombe, N. S. (2014). Finding the missing piece: Blocks, puzzles, and shapes fuel school readiness. Trends in Neuroscience and Education, 3(1), 7-13.

97. Veryeri Alaca, I. (in press) "Materiality in Picturebooks," The Routledge Companion to Picturebooks, edited by Bettina Kümmerling -Meibauer, (2017).

98. Wai, J., Lubinski, D., \& Benbow, C. P. (2009). Spatial ability for STEM domains: Aligning over 50 years of cumulative psychological knowledge solidifies its importance. Journal of Educational Psychology, 101(4), 817.

99. Wai, J., Lubinski, D., Benbow, C. P., \& Steiger, J. H. (2010). Accomplishment in science, technology, engineering, and mathematics (STEM) and its relation to STEM educational dose: A 25-year longitudinal study. Journal of Educational Psychology, 102(4), 860.

100. Weisberg, D. S., Hirsh-Pasek, K., \& Golinkoff, R. M. (2013). Guided Play: Where curricular goals meet a playful pedagogy. Mind, Brain, and Education,7(2), 104-112.

101. Wyeth, P., \& Wyeth, G. F. (2001). Electronic blocks: Tangible programming elements for preschoolers. In IFIP TC. 13 International Conference on HumanComputer Interaction (Vol. 1, pp. 496-503). IOC Press.

102. Xie, L., Antle, A. N., \& Motamedi, N. (2008, February). Are tangibles more fun?: comparing children's enjoyment and engagement using physical, graphical and tangible user interfaces. In Proceedings of the 2nd international conference on Tangible and embedded interaction (pp. 191-198). ACM. 
103. Yokota, J., \& Teale, W. H. (2014). Picture books and the digital world. The Reading Teacher, 67(8), 577-585.

104. Young, C. J., Cartmill, E. A., Levine, S. C., \& Goldin-Meadow, S. (2013). Gesture and Speech Input are Interlocking Pieces: The Development of Children's Jigsaw Puzzle Assembly Ability. In the Proceedings of The Annual Meeting of the Cognitive Science Society (2014), 1820-1825.

105. Zaman, B., Abeele, V. V., Markopoulos, P., \& Marshall, P. (2012). Editorial: the evolving field of tangible interaction for children: the challenge of empirical validation. Personal and Ubiquitous Computing, 16(4), 367-378.

106. Zosh, J. M., Verdine, B. N., Filipowicz, A., Golinkoff, R. M., Hirsh-Pasek, K., \& Newcombe, N. S. (2015). Talking Shape: Parental Language With Electronic Versus Traditional Shape Sorters. Mind, Brain, and Education, 9(3), 136-144.

107. Zuckerman, O. (2004). System blocks: learning about systems concepts through hands-on modeling and simulation (Doctoral dissertation, Massachusetts Institute of Technology).

108. Zuckerman, O., Arida, S., and Resnick, M. (2005). Extending Tangible Interfaces for Education: Digital Montessori-Inspired Manipulatives. In Proceedings of the SIGCHI conference on Human factors in computing systems (pp. 859-868). ACM.

109. Zuckerman, O., \& Gal-Oz, A. (2013). To TUI or not to TUI: Evaluating performance and preference in tangible vs. graphical user interfaces. International Journal of Human-Computer Studies, 71(7), 803-820. 